SHORT REPORT

\title{
Difference in injury pattern between drivers and front seat passengers involved in road traffic accidents in Scotland
}

\author{
D K Pedley, S Thakore
}

Emerg Med J 2004;21:197-198. doi: 10.1136/emj.2003.012369

Objectives: To investigate the frequency and pattern of injury in front seat passengers as compared with drivers, in Scotland.

Methods: Using the Scottish Trauma Audit Group (STAG) database from 1994 to 2000, a search for injuries to eight anatomical body regions was performed. Injuries were identified and selected by their abbreviated injury score code. A comparison of injury frequency between drivers and front seat passengers was then made.

Results: There were 4189 drivers and 954 front seat passengers included in the study. Mortality was higher in the "front seat passengers" group $16.6 \%$ compared with $5.3 \% p=0.13)$. Seven of the eight body regions selected showed higher rates of injury in front seat passengers. There were significantly more injuries to cervical spine $16.0 \%$ compared with $3.3 \% p \leqslant 0.001)$, chest $(41.4 \%$ compared with $29.0 \% p \leqslant 0.001)$, and lumber spine $(7.4 \%$ compared with $5.2 \% p \leqslant 0.001$ ) in front seat passengers.

Conclusions: Front seat passengers are at increased risk of injury relative to drivers in actual road traffic accidents as recorded in the STAG database. This contradicts crash test data, which suggest drivers are less well protected than front seat passengers in laboratory conditions.

1 mprovements in car design with specific attention to safety have resulted in a reduction in rates of death and serious injury as a result of road traffic accidents. Car manufacturers use crash test data to indicate vehicle safety performance, with the traditional view that drivers are more vulnerable to injury than front seat passengers (FSPs) being supported by data from the European new car assessment programme (Euro NCAP). ${ }^{1}$ However, crash tests reflect the level of protection afforded to drivers and FSPs rather than injuries sustained in road traffic accidents. In the United Kingdom and North America, lateralisation of injury has only been investigated in the context of blunt diaphragm rupture. ${ }^{2}{ }^{3}$ This study aims to investigate the frequency and pattern of injury in FSPs as compared with drivers, in Scotland.

\section{METHODS AND RESULTS}

Analysis of the Scottish Trauma Audit Group (STAG) database from 1994 to 2000 showed that 5143 drivers or FSP patients were injured as a result of a road traffic accident. A search for injuries to eight anatomical regions was performed. Regions chosen were similar to those in crash test studies. ${ }^{1}$ Injuries were identified and selected by their abbreviated injury score (AIS) code. $^{4}$ Table 1 shows a comparison of injury frequency between drivers and FSPs. Statistical analysis was by $\chi^{2}$ test; a p value of less than 0.05 was assumed to correlate with a significant difference in rates of injury.

There were 4189 drivers and 954 FSPs included in the study. Mortality was higher in the "front seat passengers" group (table 1). Seven of the eight body regions selected showed higher rates of injury in FSPs. There were significantly more injuries to cervical spine, chest spine, and lumber spine in this group. Of the 66 specific injury types (AIS coding) five were not observed. Significant differences were found in eight injury types all of which suggest the injury was more frequent in passengers (table 1).

\section{COMMENT}

In Scotland there were 1973 accidents resulting in fatal or serious injury during the year 2000. Rates of serious injury are consistently higher in Scotland compared with England and Wales. ${ }^{5}$ Analysis of a large high quality database shows that higher rates of death and serious injury occur in FSPs than in drivers involved in road traffic accidents. The strength of such database information is that it reflects actual rather than hypothetical events. This contradicts crash test data that suggest drivers are less well protected than FSPs in laboratory conditions. ${ }^{1}$ Intuitively, it would seem that the driver of a car would be more vulnerable to injury, because of the proximity of the steering wheel. It may be that in modern cars the steering wheel is a protective factor. Information regarding driver and passenger airbag deployment, and the presence or absence of side impact protection systems, may have provided insight into the disparity between driver and FSP injuries. This information was not available from the database. The attention given to driver protection in the form of driver's side air bags and similar safety measures has improved the level of driver protection. The lack of a steering wheel may result in greater forward momentum in FSPs leading to greater force transfer, focused on the areas of restraint-that is, chest and abdomen. The comparatively higher incidence of spinal injuries may be attributable to hyperflexion as a result of this greater forward momentum. Evidence from previous studies suggests seatbelt wearing behaviour may be influenced by age and sex; this could be a factor influencing injury in FSPs. ${ }^{6}$ It is worth noting that the STAG database excludes patients below 16 years old

Another possible explanation is that a driver, being in control of the car, is in a position to take evasive action. The precise mechanism of the road traffic accident will have an influence on the pattern of injury sustained. Although details of individual crash scenes are not available from the database, in such a large sample it is probable that every common mechanism will be represented, reflecting real life events.

Abbreviations: STAG, Scottish Trauma Audit Group; AIS, abbreviated injury score; FSP, front seat passenger 


\begin{tabular}{|llll}
\hline Table 1 Analysis of injury patterns & & \\
\hline Body region (specific injury) & Drivers (n=4189) & Front seat passengers (n=954) & p Value \\
\hline Head & $606(14.5)$ & $145(15.2)$ & 0.58 \\
Face & $402(9.6)$ & $86(9.0)$ & 0.62 \\
Chest & $1216(29.0)$ & $395(41.4)$ & $<0.001$ \\
(tension pneumothorax) & $0.3 \%$ & $0.8 \%$ & 0.021 \\
(isolated rib fractures) & $9.4 \%$ & $12.8 \%$ & 0.002 \\
(sternal fractures) & $7.8 \%$ & $18.1 \%$ & $<0.001$ \\
Abdomen & $250(6.0)$ & $70(7.3)$ & 0.12 \\
(colon rupture) & $0.3 \%$ & $0.8 \%$ & 0.042 \\
(mesenteric laceration) & $1.1 \%$ & $2.1 \%$ & 0.025 \\
Cervical spine & $183(4.4)$ & $69(7.2)$ & $<0.001$ \\
(c-spine fracture) & $3.3 \%$ & $6.0 \%$ & $<0.001$ \\
Thoracic spine & $212(5.1)$ & $54(5.7)$ & 0.47 \\
(t-spine fracture cord laceration) & $0.0 \%$ & 0.2 & 0.034 \\
Lumbar spine & $218(5.2)$ & $71(7.4)$ & 0.0008 \\
(l-spine fracture) & $5.0 \%$ & $7.3 \%$ & 0.05 \\
Pelvis & $597(14.3)$ & $141(14.8)$ & 0.68 \\
Overall mortality & $224(5.3)$ & $63(6.6)$ & 0.13 \\
\hline Percentages are shown in parentheses. & & \\
\hline
\end{tabular}

In contrast with crash test data, FSPs are at increased risk of injury relative to drivers in actual road traffic accidents as recorded in the STAG database. Information from crash test studies should be examined in conjunction with data indicating real life car safety performance. In addition, it may now be necessary to turn the spotlight of car safety design towards passenger protection.

\section{ACKNOWLEDGEMENTS}

Thanks to Rik Smith and Diana Beard of the Scottish Trauma Audit Group for their help with data analysis.

\section{Contributors}

Shobhan Thakore initiated and formulated the initial study hypothesis. Diana Beard facilitated access to the STAG database. Rik Smith performed the statistical analysis. David Pedley wrote and submitted the paper.

\section{Authors' affiliations}

D K Pedley, S Thakore, Accident and Emergency Department, Ninewells Hospital and Medical School, Dundee, UK
Correspondence to: Dr D Pedley, Accident and Emergency Department, Ninewells Hospital and Medical School, Dundee DDI 9SY, UK; dpedley@doctors.org.uk

Accepted for publication 30 October 2003

\section{REFERENCES}

1 European new car assessment program. (http://www.euroncap.com).

2 Thakore S, Henry J, Todd AW. Diaphragmatic rupture and the association with occupant position in right-hand drive vehicles. Injury 2001;32:441-4

3 Kearney PA, Rouhana SW, Burney RE. Blunt rupture of the diaphragm: mechanism, diagnosis, and treatment. Ann Emerg Med 1989;18:1326-30.

4 Committee on injury scaling, Association for the Advancement of Automotive Medicine. The abbreviated injury scale, 1990 revision. Des Plaines, Chicago: Association for the Advancement of Automotive Medicine, 1990.

5 Scottish Office. Road accidents Scotland 2000. (http:// www.scotland.gov.uk/stats/bulletins/00122-00.asp).

6 Lerner EB, Jehle DV, Billittier AJ 4th, et al. The influence of demographic factors on seatbelt use by adults injured in motor vehicle crashes. Accident Analysis and Prevention 2001:33:659-62.

7 Valent F, McGwin G Jr, Hardin W. Restraint use and injury patterns among children involved in motor vehicle collisions. J Trauma 2002;52:745-51. 